\title{
Coupled Fe and Si cycle in the Precambrian ocean
}

Xin-Yuan Zheng

${ }^{1}$ Department of Earth and Environmental Sciences, University of Minnesota-Twin Cities, Minneapolis MN 55455, USA (zhengxy@umn.edu)

Much attention in the past two decades has been devoted to study of $\mathrm{Fe}$ cycling in early oceans using stable $\mathrm{Fe}$ isotopes, because the oxidation state of $\mathrm{Fe}$, which can be inferred from $\mathrm{Fe}$ isotope ratios in certain geological records, was tightly linked to redox conditions of Earth's surface environments, and, hence, to evolution of life. In marked constrast, cycling of silicon in early oceans has not received as much attention, even though it is widely accepted that Precambrian seawater had much higher $\mathrm{Si}$ concentrations relative to the modern level due to the absence of silicifiers at that time. This is manifested by abundant Precambrian quartz-rich rocks of a sedimentary origin, such as cherts and banded iron formations (BIFs).

A series of microbial and abiological experiments were conducted to better understand $\mathrm{Si}$ isotope fractionation in systems pertinent to formation of cherts and BIFs [1-3]. The results provide a refined framework for interpreting $\mathrm{Si}$ isotope data recorded in Precambrian sedimentary rocks and have significant implications for using this isotope system as a proxy for the ancient Si cycle. Surprisingly, the laboratory results imply that $\mathrm{Si}$ isotope data from Precambrian cherts and BIFs reflect a tight coupling between $\mathrm{Fe}$ and $\mathrm{Si}$ cycle in early oceans, consistent with recent claims based on detailed mineralogical studies on these rocks [e.g., 4]. This revised view can lead to unique constraints from the prospective of a non-redox sensitive element, $\mathrm{Si}$, on cycling of a redox sensitive element, Fe, and possibly other nutrient elements in early Earth. Re-interpretation of Precambrian Si isotope records, made possible through improved mechanistic understanding of $\mathrm{Si}$ isotope fractionation from low temperature experiments, provides new insights into secular changes in continental weathering and reverse weathering. I would like to highlight the importance of laboratory experiments in constraining fundamental behaviors of the socalled non-traditional stable isotopes, based on which new interpreations of exisiting isotope records in natural sampels may transform our previous understanding of co-evolution of the Earth and life.

[1] Zheng et al., GCA, 2016; [2] Reddy et al., GCA, 2016; [3] Zheng et al., GCA, 2019; [4] Rasmussen et al., Geology, 2015 